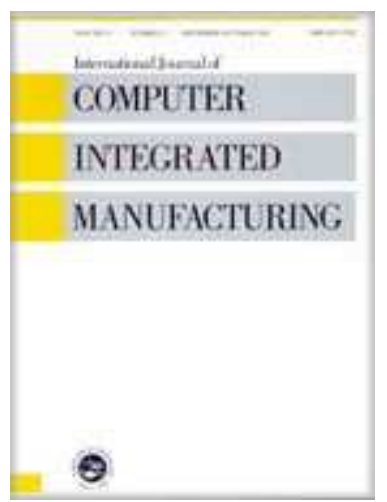

\title{
A Method for Engineering Design Change Analysis Using System Modelling and Knowledge Management Techniques
}

\begin{tabular}{|r|l|}
\hline Journal: & International Journal of Computer Integrated Manufacturing \\
\hline Manuscript ID: & TCIM-2010-IJCIM-0127.R1 \\
\hline Manuscript Type: & Original Manuscript \\
\hline Author: & 18-Jan-2011 \\
\hline Complete List of Authors: & $\begin{array}{l}\text { Fei, Genyuan; University of Greenwich, School of Engineering } \\
\text { Gao, James; University of Greenwich, School of Engineering } \\
\text { Owodunni, Dele; University of Greenwich, School of Engineering } \\
\text { Tang, Xiaoqing; Beihang University, School of Mechanical } \\
\text { Engineering and Automation }\end{array}$ \\
\hline Keywords: & $\begin{array}{l}\text { PRODUCT DESIGN, ENGINEERING MANAGEMENT, PRODUCT } \\
\text { MODELLING, CIM }\end{array}$ \\
\hline Keywords (user): & Change management, Knowledge management \\
\hline &
\end{tabular}

\section{SCHOLARONE Manuscripts}




\section{A Method for Engineering Design Change Analysis Using System Modelling and Knowledge Management Techniques}

Authors: Genyuan $\mathrm{Fei}^{\mathrm{a}}$, James Gao ${ }^{\mathrm{a}}$ (corresponding author), Oladele Owodunni $^{\mathrm{a}}$, Xiaoqing Tang ${ }^{\mathrm{b}}$

${ }^{a}$ Centre for Innovative Product Development, School of Engineering, University of Greenwich, Chatham Maritime, Kent, ME4 4TB, UK

Tel: +44(0)1634883341, Fax: +44(0)1634883153

Email addresses: j.gao@gre.ac.uk

${ }^{b}$ School of Mechanical Engineering and Automation, Beijinghang University, Beijing, 100083, China 


\title{
A method for engineering design change analysis using system modelling and knowledge management techniques
}

\author{
(Received 02 September 2010, Revised on $19^{\text {th }}$ January 2011)
}

\begin{abstract}
Engineering design change management is very important to the success of engineering product development. It has been recognised that the earlier change issues are addressed, the greater product lifecycle costs can be saved. However, in practice most engineering changes happen in the manufacturing phase, the later phase of product development. Change issues happening in the design phase, especially between the functional and the structural domains, have been a research focus in recent years, and thus there is significant research work that has been carried out to resolve early engineering change issues from different perspectives. This paper presents a novel methodology that has been developed to help designers trace, analyse and evaluate engineering changes occurring in the product design phase. A modelling method is employed to enhance the traceability of potential design changes occurred between the functional and structural domains of design. Based on functional and physical models, a matrix based method is developed to analyse change propagations between components and help find out design conflicts arising from design changes. A knowledge based method has been proposed to resolve design conflicts by reusing previous design change knowledge. An industrial example about changes of a wind turbine cooling system has been used to help understand the methodology and prove its usefulness.
\end{abstract}

Keywords: engineering design, change management, system modelling, design conflict solving, knowledge management system

\section{Introduction}

Engineering changes have been recognised as inevitable in complex engineering product

development (Huang, Yee and Mak 2003, Palani Rajan, Van Wie, Campbell, Wood and Otto

2005, Keller, Eckert and Clarkson 2009). They have great influences on downstream

developing and production activities, thus making product development very costly and time

consuming (Huang, Yee and Mak 2003). Therefore, it is critical to keep them under control.

Engineering changes have also been recognised as a source of innovation and creativity which

can facilitate evolutions of products and technologies (Balogun and Jenkins 2003, Jarratt,

Eckert, Weeks and Clarkson 2003, Eckert, Clarkson and Zanker 2004). From this perspective,

knowledge acquired from engineering changes is also very useful to product development in 
International Journal of Computer Integrated Manufacturing

the long term. Despite of the different perspectives, both of the two arguments reflect the importance of engineering change management in product development.

In the past, a lot of research has been done in engineering change management (ECM) regarding computerising traditional paper-based engineering change processes (Huang, Yee and Mak 2001), improving communicating methods between engineers (Shiau and Wee 2008), clarifying knock-on change effects between components (Eckert, Keller, Earl and Clarkson 2006, Clarkson, Simons and Eckert 2004). Most early research shows the efforts made in dealing with engineering changes in the manufacturing process. Recently, changes happening in the critical stage of product development, the product design stage, have been emphasised (Mckay 2003). It is recognised that the design stage of product development could determine the largest cost savings during the product life cycle. This means changes happening at the design stage would have a greater impact than those happening in the manufacturing phase. This project focuses on analysis of changes and their propagations in the product design phase and solving design conflicts arising from them by using knowledge management technologies. As an important part of product development, engineering change management (ECM) has been studied by many academia and industrial practitioners in the past decade. They have identified issues within engineering change management and tackled them with proposed solutions from different perspectives. An introduction of the concept of ECM and an overview of previous research is given below.

\subsection{The Concept of Engineering Change Management}

Although engineering change has been studied for many years, its definition varies according to statements of different researchers. Wright (1997) defined engineering change as modification to a component of a product before it goes into production. Some researchers 
International Journal of Computer Integrated Manufacturing

agree that engineering change is modification to dimensions, fits, forms, functions and materials to product or components after the product design is released (Huang, Yee and Mak 2003, Kocar and Akgunduz 2010). Whilst some other researchers view engineering changes as changes occur in a wider range from customer requirements to product in use (Pikosz and Malmqvist 1998, Eckert, Clarkson and Zanker 2004).

While research focuses have been shifting over time, the scope of research on engineering change has been widened. The initial motive of studying ECM was to avoid engineering changes during the manufacturing process due to the adverse effects they cause. The adverse effects caused in terms of delivery time, developing cost and product quality are noticeable but very difficult to estimate (Huang, Yee and Mak 2003). Later on, people realised that engineering changes are actually inevitable. Therefore, researchers have turned to finding out how engineering changes go on and what kind of impacts they may cause (Clarkson, Simons and Eckert 2004, Kocar and Akgunduz 2010, Ouertani 2008). Recently, some researchers argue the benefit of engineering changes to innovation and creativity, which can enhance the competitiveness of companies. Thus some researchers have started to study engineering changes from perspectives of knowledge management and knowledge reuse (Balogun and Jenkins 2003, Palani Rajan, Van Wie, Campbell, Wood and Otto 2005, Lee, Ahn, Kim and Park 2006, Keese, Seepersad and Wood 2009).

The process of organising engineering change activities have also been explored in the past decade, in order to find most efficient and effective approach of engineering change management. A general process of engineering change has been proposed by Clarkson and Eckert (2005). This process includes six steps, namely engineering change request, possible solution identification, risk/impact assessment, solution selection and approval, solution 
International Journal of Computer Integrated Manufacturing

implementation, and change process review. Although the general process of engineering describes a reasonable approach to addressing change issues in product development, in reality, different companies have quite different processes to deal with engineering changes in order to fit their specific organisational and production requirements (Pikosz and Malmqvist 1998,

Eckert, Clarkson and Zanker 2004, Huang, Yee and Mak 2003).

\subsection{Change Propagation Analysis}

One of the most difficult issues in analysing engineering change is that when a component is changed it may also change its related components (Ariyo, Eckert and Clarkson 2009).

Therefore, an initial change may cause changes spreading at several structural levels. Essentially, the reason why changes propagate is because of the dependency between components. This situation is so-called change propagation or the knock-on effects of changes, which makes change analysis very tricky. Some researchers have made some efforts in dealing with this issue.

Clarkson and his colleagues have proposed a method called change prediction matrix (CMP) to trace change propagations and analyse the impacts they may cause (Clarkson, Simons and Eckert 2004). The method transforms the dependency relationship between components in a product model to a design matrix. Based on this matrix, the likelihoods that potential change propagations may happen between components are estimated. Also in the same way, the impacts of these potential change propagations may cause have also been estimated. By combining the change likelihood matrix and the change impact matrix, a change risk matrix has been generated. With help of visualising method, change propagation paths and their relative risks have been clarified. 
International Journal of Computer Integrated Manufacturing

In another study, Eckert and his colleagues (2004) have proposed a method to analyse change propagation at a parametric level and identify four types of change propagation behaviours, namely constants, absorbers, carriers, and multipliers. These four types of change propagation behaviours help to analyse change propagations that cross multi-levels. Four type of change propagation behaviours represent four situations when a change of a component propagating to another component via some other components, which includes changes being passed without effect, being reduced or eliminated, being replaced with new changes from the intermediate component, and being enhanced. This method has also been integrated with the CMP method to enhance the performance of change propagation analysis in product conceptual design (Keller, Eckert and Clarkson 2009).

Kocar and Akgunduz (2010) have proposed a different method to analyse change propagations. They use visualisation technique and data mining technique to represent product models and find out dependencies between components. Users would be warned visually if potential change propagation is predicted to happen.

Ouertani (2008) has also proposed a visualisation tool called DEPNET to model product data and their dependencies within them. By using the product data dependent relationships, changes emerging during collaborative design process would be tracked down. Do and his colleagues (2008) have also proposed a method for tracking engineering change propagation between different product data views based on a shared base product model. The method reduces data redundancy in engineering change management and maintains consistency between different product data views. 
International Journal of Computer Integrated Manufacturing

\subsection{Information Systems for ECM}

Although methods for engineering change management (ECM) have been proposed with rigorously analytical or reasoning approaches, designers will be easily exhausted before having investigated the entire search space (Ariyo, Eckert and Clarkson 2009). Therefore, it is important that computer aided tools have been developed and used in engineering change management. Previous investigations have shown that computer-aided ECM systems have been rarely utilised in companies (Pikosz and Malmqvist 1998, Huang, Yee and Mak 2003). Although some companies have used electronic documents management systems to replace paper-based ECM documents, the data are non-structural and it's difficult to semantically trace similar engineering change cases.

Although there are currently not many companies are using computer-aided systems to facilitate their engineering change management, there are some systems that have been developed by academia trying to enhance communication and information sharing in change management process. Huang (2001) developed a web-based system to implement the whole process of engineering change management, including engineering change log, engineering change request, engineering change evaluation and engineering change notice. The distributed system has improved the efficiency of ECM and enhanced the collaborations between engineers. Also structural ECM data make it possible to integrate with other computer-aided systems such as Product Data Management (PDM), Enterprise Resource Planning (ERP), Computer Aided Design (CAD) and Supply Chain Management (SCM). Ouertani and Gzara (2008) have developed a system called DEPNET to visually track dependencies within product specifications so that change propagations can be captured if any design changes of a product specification happen. As mentioned above, Kocar and Akgunduz (2010) developed a 
International Journal of Computer Integrated Manufacturing

visualisation system to track change propagation which is well integrated with $3 \mathrm{D}$ modelling system. Lee and his colleagues (Lee, Ahn, Kim and Park 2006) developed a knowledge based system to facilitate engineering change management in a collaborative environment. The authors have used ontology technology and case based reasoning method to construct a knowledge base of previous development experience. It also implements the knowledge base with a web-based system which enables users go through the whole engineering change management process from change request initiated to change approved.

\subsection{Aim and Objectives of the Project}

Based on previous research reviewed by the authors, some gaps in engineering change management have been identified. First, changes of functional requirements should be considered together with changes in the physical domain in the design phase. For example, in the domain definitions of the product design stage in the theory of Axiomatic Design (Suh 2001), when the changes in physical components are considered, the changes in the functional domain and their effects on the physical domain have not been considered. Second, there is a lack of consideration of the impact of change solutions on the change propagation analysis. A lot of efforts have been made to predicting change propagations with predefined component interactions. However, specific solutions for change requests may dramatically change predefined interacting relationships between components, which may make predictions of later changes fail. Third, there is a lack of tools to help engineering designers reuse knowledge from previous cases regarding design change management in industry. In many design change cases, technical solutions for a design change request, or say for some similar design change requests, may have been re-developed on many other occasions. That may be because experience or 
International Journal of Computer Integrated Manufacturing

technical solutions from previous design change cases have not been formalised and shared effectively.

This project therefore aims at dealing with changes in the functional domain and the physical structure domain of complex product design. It would help designers analyse design change propagations within these two domains. It would also help to solve design conflicts arising from design changes by reusing knowledge from previous design change cases. There are mainly three objectives, i.e., (1) dynamically capture changes and their propagations between functional requirements and physical structures; (2) identify and formalise design conflicts arising from design changes; and (3) use knowledge based engineering (KBE) technology to facilitate finding solutions for design conflicts from previous design cases. A method for design change management is proposed by putting the emphasis on analysis of changes in the functional requirement domain and the physical structure domain. A modelling method is employed to enhance the traceability of changes occurring between functional model and structural model. A matrix based method is constructed to capture dynamic change propagations between the two domains. In the end, a knowledge based method is developed to help to solve conflicts arising during design change analysis. An industrial example has been used to show how the method works.

\section{Analysis of Design Change Management (DCM) Practices}

Referring to literature reviewed above, most researchers focus on the engineering change analyses among physical components. Although some of them mentioned functional requirements would be influenced by changes of physical components, detailed discussion has not been made regarding how these influences happen and how to deal with them. In this section, changes taking place between the functional domain and the physical structure domain 
International Journal of Computer Integrated Manufacturing

of the product design stage have been discussed. Additionally, knowledge use during design change management at this stage has also been covered.

\subsection{Change of Functional Requirements}

Change of functional requirements may have many reasons, for example, changes of customer demands, changes of government policies, or changes of project aims for better competing with rivals (Rouibah and Caskey 2003, Clarkson, Simons and Eckert 2004). Changes occurring in functional requirements may affect three aspects of product design. (1) Functional requirement change needs to be verified according to customer requirements to make sure all the changes meet the original customer demands. As one of the most important inputs of a product design project, customer requirements should be monitored all the time during changes of functional requirements to make sure all the changes meet the original customer demands. (2) Any change of a functional requirement may result in potential changes of other functional requirements depending on the interrelationships among them. These changes will be captured in the functional requirement model so that causal impacts can be analysed and controlled. (3) Obviously, any changes in the functional requirement domain will affect physical structures which are correspondingly constructed according to functional requirements.

\subsection{Change of Physical Structures}

Change of physical structures is another important part of design change management. A lot of situations may give rise to changes in the physical structure design, for example, changes of functional requirement (discussed above), physical conflicts within solutions, solution changes on the supplier's side, technical innovation, manufacturing restrictions. Changes of physical structure may also directly affect three domains, namely the functional requirement domain, the physical structure domain itself and the manufacturing domain. In the functional 
International Journal of Computer Integrated Manufacturing

requirement domain, any changes in the physical structure may change target outputs of related functions. Since one component is possibly involved in realisations of more than one function, the relationships between components and related functions need to be clarified. Therefore, any change in the physical domain needs be verified to make sure that target functional requirements have been met. In the physical structure domain itself, components are linked together by physical connections, which make it possible to realise demanded functions. Change of a component may potentially change operations of other components, which in turn may change the realisation of related functions.

Figure 1 shows the change propagation routes within the functional domain and the physical structure domain, and the routes between them. For example, change of the functional requirement $F_{n}$ may require changes on components involved in the realisation of it, in this example let's say $C_{2}$. The change of $C_{2}$ could have influence on $C_{i}$ via some behavioural or spatial relationships between them. $\mathrm{C}_{\mathrm{i}}$ is one of the components involved in the realisation of $F_{i}$. Then $C_{i}$ needs to be checked against functional requirement $F_{i}$ to see if $F_{i}$ can be satisfied. If not, then $\mathrm{C}_{\mathrm{i}}$ or other components involved the realisation of $\mathrm{F}_{\mathrm{i}}$ may need to be changed to accommodate the influence of the previous change. These components may be also involved in realisations of other functional requirements (for example $F_{1}, F_{2}$ in the diagram) so further changes may be needed. In this diagram, change of $F_{n}$ directly cause changes of its components and also indirectly cause changes of other components and functional requirements. In the manufacturing domain, change of physical structure may change downstream activities, such as manufacturing process planning, supply chain management, risk and cost evaluation.

Impacts on these product development activities need to be analysed or re-evaluated. Although $\underline{\text { change propagation between the functional domain and physical domain looks obvious from }}$ 
International Journal of Computer Integrated Manufacturing

discussions in the last two sections, there is a lack of method for supporting tackling the change propagation process between the two domains, solving problems arising from the process and analysing change impacts. An important part of this paper is focused on developing such a method to bridge the gap. The matrix-based method for analysing change propagations has been described in section 3.

(Figure 1)

\subsection{Conflict Solving in Design Change Management}

Conflict solving is one of the most concerned issues in design change management. In many cases, changes of a component or a function may require other parts of the design to change correspondingly. Furthermore, changes of these parts would cause changes of more parts of the design. This effect is the so called change propagation or knock-on effect. Actually, the reason why a change of a part of the design causes changes of other parts is because the initial change of the design may harm or obstruct operations of other components or satisfactions of other functional targets, which can be seen as functional or structural conflicts. In other words, change propagations are caused by design conflicts. Once there is no design conflict arising from any design changes, the change propagation stops. Although many design conflicts may have been solved during the change implementation by experienced engineers, many others may not be recognised in the design phase due to the lack of systematic methods and they would have been carried over to the manufacturing phase which may cause a huge amount of cost in later phases. Therefore, an effectively analytical method is needed to identify conflicts in design change management and solve them as early as possible. 
International Journal of Computer Integrated Manufacturing

\subsection{Knowledge Use in Design Change Management}

Knowledge use is critical for design change management to ensure results from change analysis are fact-based and consistent. There are mainly three aspects where design knowledge can be used to help solve change problems.

The first aspect is to identify design change modes. The design change mode is structured records of design changes implemented in previous applications. The point of having design change modes formalised in a knowledge repository is for frontline design engineers to find out whether similar design changes have happened. They can use these similar design change cases (if there is any) as references to help to find proper solutions and estimate potential change propagations and their impacts.

The second aspect is regarding design conflict solving. During a company's daily operations, there are a lot of solutions that have been proposed by engineers in attempt to tackle design conflicts arising from product development. These solutions whether successfully implemented or just on sketches are important assets of the company which should be properly generalised and deposited in the knowledge repository of the company. Once new design conflicts emerge and there is no similar design change mode that can be referred to, engineers can follow a formalised route to try to find proper solutions for them.

The third aspect is to use design knowledge to facilitate change impact analysis. Some knowledge of physical structure development has always been studied by companies, for example knowledge regarding developing time, developing cost and developing risks of solutions, components and parts. When a design change is initiated, engineers not only need to find its solutions and solutions for propagating changes, but also have to estimate the overall impact caused by the initial design change by taking consideration of time, costs and risks for 
International Journal of Computer Integrated Manufacturing

development of new solutions. Therefore, decisions can be made for whether it is worth proceeding or not, or which parts of these solutions need to be modified, in order to make sure the change impact will not be too heavy to afford.

\section{The Proposed Methodology}

\subsection{Analysis of the DCM Process}

There are three types of relationships existing in a product design, i.e., mapping relationship between functional requirements and physical structures, physical interaction relationship between structures, and spatial connection relationship between structures (Christophe, Bernard and Coatanéa 2010). These relationships within product design largely cause change propagations. The method of design change management proposed in this paper is based on analyses of these three types of relationships.

The process of design change management has been depicted in Figure 2 . The whole process can be divided into three main steps: (i) system modelling of the product design; (ii) change propagation analysis based on the composite matrix; and (iii) knowledge-based design conflict solving.

In the system modelling step, the product design with change (initial or propagated) applied has been modelled by three types of models, i.e., the functional structure model (in the form of SysML block definition diagram), the physical interaction model (in the form of SysML activity diagram) and the spatial connection model (in the form of CAD model). Each model clarifies one aspect of the product design correspondingly. By synthesising the relationships obtained from these three models, a composite matrix has been generated which is critical to change propagation analysis. Differing from other matrix-based methods in some research in change propagation analysis, the composite matrix combines three types of 
International Journal of Computer Integrated Manufacturing

relationships of the design together and provides an intuitive and dynamic way to capture change impacts across components and their functions. Explanation of each step is given in section 3.3 .

In the change propagation analysis step, the design change has been examined by checking changes to related flows (representing interactions between components) and spatial connections. Any components connected with these flows and spatial connections are then examined with functions that they serve for. If the effects on the components, which are caused by changes of those flows and spatial connections, make realisations of corresponding functions fail, it means there are design conflicts existing which are caused by the design change. Design conflicts are then identified during the analysis with the composite matrix. The process of change propagation analysis using the composite matrix is described in detail in section 3.4.

In the knowledge-based design conflict solving step, design knowledge which is acquired from previous design cases is used to help solve design conflicts identified in the last step. Firstly, design conflicts are formalised by using pre-defined engineering ontology. Secondly, the formalised design conflicts are reasoned in the knowledge repository by semantically comparing with formalised general design cases stored in the knowledge repository. General solutions in the knowledge repository are formalised by the same set of the pre-defined engineering ontology. Thirdly, a prioritised list is generated with the most semantically similar general solutions at the top and the designers check those general solutions starting from the top of the list and their related design cases to find reference $\underline{\text { solutions for the design conflicts. At last, based on the reference solutions, proper solutions are }}$ worked out by designers and change decisions are made. The design with changes generated in 
International Journal of Computer Integrated Manufacturing

this step will be re-modelled and further possible change propagation are analysed again as

what is done in the last two steps.

(Figure 2)

\subsection{The Industrial Example Used}

The industrial example used in this project to evaluate the proposed methodology is a cooling system which is a critical part of a wind turbine (Figure 3). This new model of wind turbine is under development in our collaborative company which is a pioneer in gearless wind turbine development. Nearly 2000 wind turbines (by May 2010) based on their solutions have been deployed in Europe, Asia and America. There is a real design change scenario that the wind turbine needs to be deployed in a very sandy environment so that air filtering measure of the cooling system needs to be suppressed to prevent more sands than normal from coming to the cooling system and damaging it. This change causes some knock-on effects that give rise to changes on other parts of the system. The methodology proposed in this paper is going to be used to solve this problem by modelling the cooling system, identifying design changes and related design conflicts, and solving design conflicts by using a knowledge-based system.

\section{(Figure 3)}

\subsection{Modelling Methods Used in this Project}

Modelling of engineering design includes three parts, namely functional structure model, physical interaction model and physical structure model. In this paper, modelling methods for functional structure and physical interaction are adopted from SysML ${ }^{\mathrm{TM}}$ which is a comprehensive system engineering modelling language (Object Management Group 2008). The reason of using SysML ${ }^{\mathrm{TM}}$ is because it is a standard modelling method having intuitively visual presentations, standard descriptive language and well software tool support. It can be 
International Journal of Computer Integrated Manufacturing

easily understood by both of human and computer. That is important for this project since the methodology needs to be computerised to enhance its usability. For this reason, SysMLTM is better than other modelling methods. Modelling of physical structure can be carried out by CAD systems, which will not be an emphasis in this paper.

The functional structure is modelled by the block definition diagram (BBD) of SysML ${ }^{\mathrm{TM}}$ (Figure 4 depicts the functional structure of the cooling system). The BBD is used to model the hierarchically structural relationship of functions. It also helps to clarify the specifications of each function. The specification attribute of a function quantitatively or qualitatively represents what the function has to do, which is analysed by engineer from initial customer requirements or other requirements from various sources (e.g., technical restriction, management and government). Specifications are represented as attribute-value (could be precise value, value range or qualitative description) pairs. All of the sub-functions need to perform to meet their corresponding specifications so that specifications of their parent function can be met. Any changes to components need to be verified against its corresponding functional specifications to check whether these changes affect the realisation of functions. If

functional specifications cannot be satisfied due to these changes then other consequent changes need to be carried out.

Physical structure modelling carried out by CAD systems is intended to clarify the spatial relationship between components. When changes to a component happen, the spatial relationship helps designers find potential changes to neighbouring components based on their positions. The spatial relationship concerned in this model is all about static or kinematic connections between components, which is based on assembly relationships, but does not $\underline{\text { involve any flow-based physical interactions. }}$ 


\section{International Journal of Computer Integrated Manufacturing}

Physical interaction relationship is modelled by the internal block diagram (IBD) to clarify the behavioural relationship between components. Figure 5 shows the interaction model of the cooling system. There are a variety of flows going through components, including energy flows, material flows and signal flows. A change on a component may cause changes of the flows going through it, which may also cause changes of upstream and downstream components involved in these flows. That is because the status changes of these flows may result in components not satisfying their corresponding functional requirements.

(Figure 4)

(Figure 5)

In order to be computerised, matrix analysis is employed to represent change propagations within and between functional requirement domain and physical structure domain. A composite matrix is constructed based on the results of modelling analyses of functional structure, physical interaction and physically spatial relationship (Figure 6). The matrix is composed of three parts which are marked by different colours. The first part (the green part) represents the mapping relationship between function and components. Elements in the first column represent physical components and elements in the green part of the first row represent functions. Each marked cell in the green part represents the involvement of a component in the realisation of a function. The second part (the blue part) represents the interaction relationship between components, which reflects the modelling results of physical interactions between components. Elements in the blue part of the first row represent flows in Figure 5. When there are changes happening on a component (an element in the first column), related flows going through it will be identified in the matrix. Components that these flows go through are also identified. The third part (the grey part) represents the physically spatial 
International Journal of Computer Integrated Manufacturing

relationship between components. A marked cell in this part the matrix means the component in the column is physically connected with the component in the row. Clarification of this type of relationship helps designers find potential propagating changes to neighbouring components. The next section presents further explanation of how potential propagating changes are identified.

(Figure 6)

\subsection{Identifying Change Propagation and Design Conflicts}

Change analysis is intended to uncover changes and their propagations by following connections within functional requirements and physical components and relationships between them. This section shows the idea of identifying change propagations and their impacts arising from a change of a component. The description of the method is associated with a scenario of improving air filtering as mentioned above and based on the composite matrix of change analysis (Figure 6). The process of identifying change propagation is described in the following steps. In this scenario, the change is triggered by a functional requirement called 'F2: Filter hot air'. Therefore, the analytical process starts from the function-component part of the matrix (the green part).

Step 1: Identify component changes caused by functional change. As mentioned above, because of the sandy environment where the wind turbine will be deployed, the current air filtering measure cannot meet the new functional requirement. In Figure 6, it shows components involved in the realisation of function, filter hot air (F2). In this case, there is just one component (C2, air filter mat) identified. To meet the sandy environment, the current air filter mat with a dust holding capacity $650 \mathrm{~g} / \mathrm{m}^{2}$ needs to be changed to a more effective one with dust holding capacity $750 \mathrm{~g} / \mathrm{m}^{2}$. 


\section{International Journal of Computer Integrated Manufacturing}

Step 2: Identify potential affected components. The component changed in the above step may change the physical statuses of flows going through it and also it may change its neighbouring components due to changes of its spatial characteristics. Led by component $\mathrm{C} 2$, the row shows flows and neighbouring components that are potentially affected by the change of C2. In this case, flow FL1 (air from the generator) and neighbouring component C1 (inner air incoming pipe) are related to $\mathrm{C} 1$. The flow FL1 also goes through $\mathrm{C} 1, \mathrm{C} 3, \mathrm{C} 4, \mathrm{C} 5$, so these 4 components may also be potentially affected by the change of $\mathrm{C} 1$. The side effects of changing the air filter mat is that the mat with higher dust holding capacity is thicker and it causes larger air pressure drop, which can significantly reduce the efficiency of heat exchanging.

Step 3: Check change effects with related functions. Components that are affected by the flows and the spatial connections need to be checked whether the changed flows or the changed spatial connections would affect the realisations of their related functions. In this case, the air flow after the filter mat has a lower pressure which means components $\mathrm{C} 3, \mathrm{C} 4$ and $\mathrm{C} 5$ would be potentially affected since the status of air through them is changed (see the column led by FL1). According to the analysis by engineers, the lower air pressure through C3 (inner fan) will weaken its performance. Also the lower air pressure through $\mathrm{C} 4$ (air heat exchanger) will reduce the efficiency of heat exchange. But it has almost no effect on C5 (the inner air outgoing pipe). The spatial change (thicker filter mat) has been considered as not noticeable change on $\mathrm{C} 1$ (inner air incoming pipe) since the change can be easily accommodated by the current design. Although in this case change caused by spatial connection is negligible, in many other cases it may be significant and corresponding changes need to be made. For example, in this case, change the component $\mathrm{C} 1$ or add some other structures to accommodate 
International Journal of Computer Integrated Manufacturing

the changes caused by spatial connections. Therefore, in this case, $\mathrm{C} 3$ and $\mathrm{C} 4$ have been identified as affected components which need to be changed to accommodate the previous change on $\mathrm{C} 2$.

Step 4: Identify and solve design conflicts. By analysing affected components, design conflicts can be identified. Taking $\mathrm{C} 4$ as an example, the changed input flow is the incoming air pressure which is lowered and the affected parameter is the heat exchange efficiency which is also lowered. The effect means the heat exchange cannot meet the functional requirement F4. Therefore this design conflict needs to be solved. In this paper, we develop a knowledge based method to help designers find reference solutions from previous design cases. Detailed discussion of how to solve design conflicts using a knowledge based method is presented in section 3.3 .

Step 5: Analyse change propagations caused by component changes in step 4 . When a proper solution has been found in step 4, changes on affected components have been determined. These changes would potentially affect other components as well. In the above case, if component $\mathrm{C} 4$ has been changed flows FL1, FL2 and connected components C2, C6 may also be potentially affected. Thus, a next round of change analysis also needs to be carried out until there is no further change effect being identified, which means change propagation stops and change analysis initiated by the first change is finished.

\section{Knowledge System Support for Design Conflict Solving}

As the authors argued above, the reason why design changes propagate is that there are design conflicts between components when one or some of them changed. TRIZ, which is originated from Russia, is a set effective problem solving methods (Altshuller 1996). The contradiction matrix and invention principles are useful tools of TRIZ for solving technical conflicts. The 
International Journal of Computer Integrated Manufacturing

idea of TRIZ to solve conflicts includes generally four steps: (1) identify technical conflicts;

(2) generalise technical conflicts by using 39 engineering parameters; (3) find invention

principles via a standard contradiction matrix; (4) explore specific solutions by following the indications of invention principles (Altshuller 1996, Fey and Rivin 2005). Although techniques of problem solving of TRIZ are innovative and inspirational to engineers, the method is difficult to master without a lot of trainings and long-time experience.

In this paper, the authors proposed a knowledge-based method working in a similar way

Deleted: knowledge base but more intuitive and easier to use. When a specific design conflict is identified during the change analysis, it will be formalised by referring to a set of predefined ontology. Then the formalised design conflict will be reasoned in the knowledge repository to find semantically similar generalised design cases. Therefore specific design cases which are associated with generalised design cases can be retrieved. These selected design cases will be used as reference solutions for the current design conflict. Figure 7 depicts the process of how design conflicts have been solved.

(Figure 7)

\subsection{Formalisation of Design Conflicts}

\subsubsection{Design conflict}

Design conflicts are identified in the change propagation analysis based on the composite matrix. Occurrence of design conflict has been simply depicted in Figure 8 in order to help understand the idea. Given that component 2 is one of the components serving a function, when there is a change request applied to a component (conponnet1) which has interactional connection with componnet2, it may change the input flow of component 2 , which may further affect its output flow. If the affected output flow cannot satisfy the requirement of the, then it's 
International Journal of Computer Integrated Manufacturing

said that there is design conflict occurring at component 2 which is caused by the previous change request to component1.

(Figure 8)

\subsubsection{Formalising design conflict with predefined ontology}

Formalising a design conflict is actually not formalising the design conflict itself. In fact, it's about formalising the interactional model (called the meta-interactional-model) of the component where the design conflict occurs. Figure 9 shows formalisation of a metainteractional-model,

\section{(Figure 9)}

A meta-interactional-model includes a physical component where the conflict happens, the changed input flows and affected output flows. Both the input flows and the output flows are formalised by the flow ontology and characteristics ontology (ontology depicted in Figure 10). The flow ontology defines the type of the flow. The characteristics ontology defines the properties of the flow, For example, the gas flow normally has properties like pressure, temperature, moisture, etc. Properties formalised in this part should be critical to the operation of the component. Concepts of the characteristics ontology (a node of the ontology structure) are associated with concepts of the flow ontology in the form of their properties (shown in Figure 10)

The component is also formalised by the behaviour ontology and the component ontology. The behaviour ontology defines what the component does with the input flows and generates the output flows. The component ontology defines which type of components it is. The component ontology contains related component characteristics as its properties. These component characteristics are critical for the performance of the operation of the component.

\begin{tabular}{l} 
Deleted: Design conflicts, identified \\
through the matrix-based analysis in the \\
above section, need to be formalised with \\
defined ontology which is the basis of the \\
knowledge system. \\
Deleted: the \\
\hline Deleted: design conflict \\
\hline Deleted: design conflict \\
\hline Deleted: s \\
\hline Deleted: that cause the conflict \\
\hline Deleted: that are affected by the \\
changed input flows \\
\hline Deleted: the behaviour ontology \\
\hline Deleted: the \\
\hline Deleted: ontology \\
\hline Deleted: the \\
\hline Deleted: possesses \\
\hline
\end{tabular}

Deleted: The behaviour ontology defines the how the flow is changed, which is used with the characteristics and/or other flows or objects.

Deleted: functional

Deleted: functional

Deleted: and what object the component uses while it operates

Deleted: is also

Deleted: defined by the component ontology which is also associated with the characteristics ontology 
International Journal of Computer Integrated Manufacturing

For example, in the cooling system, there are two characteristics of the heat exchanger are important to its functionality. One is the area of the heat exchanger surface. Wider surface can have a higher heat exchanging efficiency. The other one is the material that the heat exchanger is made of. Some material, for example bronze, has a better heat conduction performance than some others, for example steel.

The flow ontology and the behaviour ontology used in this paper are adopted from the work of Hirtz and his colleagues (Hirtz, Stone, McAdams, Szykman and Wood 2002). They proposed a functional ontology, so called functional basis, contains generalised functions

Deleted: The functional Deleted: ontology Deleted: is

Deleted: This

Deleted: The functional ontology includes three types of ontology, namely the behaviour ontology and the flow ontology.

Deleted: ontology to classify products, subsystems and

Deleted: s

Deleted: wind turbine

Deleted: Examples for these ontologies can be found in system implementation section.

Deleted: develop

Deleted: proposed

Deleted: for engineering design change management ontology development.

Figure 10 shows some parts of the ontology, including definitions of flows, definitions of behaviours, and definitions of components.

(Figure 10 )

Deleted: and an instance of a flow in the cooling system

Deleted: 9

\subsection{The Knowledge System for Design Conflict Solving}

Figure 11 shows the framework of the knowledge base for design conflict solving. When a design conflict arises from design change analysis, it is formalised in the way as discussed in section 4.1. The formalised model of the design conflict will then be thrown into the

Deleted: arising
Deleted: and generalised by using the
functional ontology and
product/component ontology to specify
the essences of input flows, output flows,
and functionalities
Deleted: generalised


knowledge system. The system will reason in the knowledge repository by analysing the semantic similarities between different concepts to find most similar generalised design cases. After that, design cases associated to these generalised design cases will be retrieved as reference solutions for the current design conflicts. Designers can adjust or adopt retrieved reference solutions to solve current problems. The method of generalising design cases is as the $\underline{\text { same as the way formalising meta-interactional-model. It collects design cases and formalises }}$ their target problems or functions. The generalised design cases work as indices of those associated physical design cases.

In this system, design cases are collected from many sources including different functional departments and IT systems. The design cases are formalised in a hierarchical way, which clarifies functions or problems a design case is to address, the solutions used in this design case, the components involved in this solution and characteristics that contribute to the realisation of the function or the problem solving. The formalised structure is also been generalised by the predefined ontology

(Figure 11 )

\subsection{Reasoning method for design conflict resolving}

The reasoning method is critical to finding reference solutions for design conflicts arising from design change propagation analysis. The general approach to solving design conflicts is depicted in Figure 12 .

$\underline{\text { (Figure 12) }}$

In the reasoning method, one of the most important steps is to analyse semantic similarities between formalised design conflicts and generalised design cases stored in the knowledge repository. Given that a design conflict is defined as a definition (D) and all of the
Deleted: base

Deleted: functional and physical descriptions

Deleted: solutions

Deleted: attached

Deleted: descriptions

Deleted: similar

Deleted: solutions
Deleted: $\mathrm{t}$

Deleted: domain

Deleted: including functional

ontology, component ontology and product ontology

Deleted: Therefore, the analysis of design conflict can be generalised by the same domain ontology and then find general solutions for that. The general solution can also be specified by following the relationship between the domain ontology and design cases.

Deleted: 10

Formatted: Heading 2
Formatted: Follow-on paragraph style 
International Journal of Computer Integrated Manufacturing

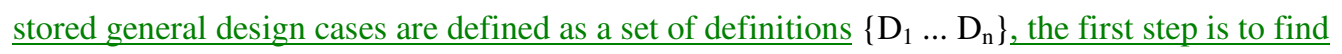
$\underline{\text { the most similar solutions from the set of general design cases. The algorithm of calculating the }}$ $\underline{\text { semantic similarities between a formalised design conflict and a generalised design case is }}$ comparing the semantic similarity of each corresponding element and then adding them up to get an overall semantic similarity.

Deleted: that

(Figure 13)

Formatted: Centered

Figure 13(a) represents hierarchically ontological definition of a group of concepts.

The higher of levels a concept stays in, the more general semantic meaning it represents. While $\underline{\text { in lower levels, the semantic meaning of a concept is more specific. In Figure } 13(\mathrm{~b}), \mathrm{IC}(\mathrm{S} 1)}$ represents the semantic meaning of the concept S1. Since S1 is the parent of S11 and S12, S1 has a wider semantic meaning than S11 and S12, which means:

$\mathrm{IC}(\mathrm{S} 11) \in \mathrm{IC}(\mathrm{S} 1)$, and IC(S12) $\in \mathrm{IC}(\mathrm{S} 1)$

Theoretically, the following equation can represent how S11 (a child) is semantically $\underline{\text { similar to S1 (a parent) by comparing scales of semantic meaning of each concept: }}$

$\operatorname{Sim}(\mathrm{S} 11, \mathrm{~S} 1)=\mathrm{IC}(\mathrm{S} 11) / \mathrm{IC}(\mathrm{S} 1)$

While the similarity of S11 (a brother) to S12 (a brother) can be expressed as:

$\operatorname{Sim}(\mathrm{S} 11, \mathrm{~S} 12)=(\mathrm{IC}(\mathrm{S} 11) \cap \mathrm{IC}(\mathrm{S} 12)) / \mathrm{IC}(\mathrm{S} 12)$

While in reality, it is well-known that exact semantic meaning of a concept is very $\underline{\text { difficult to measure. More often than not, people can tell the qualitative similarity between two }}$ concepts by their experience and common sense. Particularly, people in the professional area are better to tell similarities between concepts of professional terms some of which are not $\underline{\text { normally used by people out of the area. So in this research, a survey is developed and }}$ $\underline{\text { experienced engineers are interviewed to rate semantic similarities between child-concepts and }}$

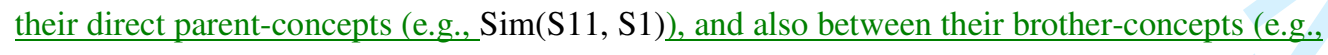


International Journal of Computer Integrated Manufacturing

$\operatorname{Sim}(\mathrm{S} 11, \mathrm{~S} 12))$. The survey and the rating process is a multi-criteria decision making process $\underline{\text { which is not discussed in details in this paper. }}$

With rated similarities between parent-child concepts and brother concepts, the similarity of any two concepts (e.g., S111 and S22) can be expressed as:

$\operatorname{Sim}(S 111, S 22)=\{\operatorname{Sim}(S 111, S 11) \times \operatorname{Sim}(S 11, S 1) \times \operatorname{Sim}(S 1, S 2) \times \operatorname{Sim}(S 22, S 2)\}$

Based on the ideas of rating and calculating similarities between concepts, the

similarity between a formalised design conflict and a generalised design case can be described as:

$\begin{aligned} \operatorname{Sim}(\mathrm{DC}, \mathrm{GD})= & \left\{\operatorname{Sim}\left(\mathrm{CF}_{\mathrm{DC}}, \mathrm{CF}_{\mathrm{GD}}\right) \times \operatorname{Sim}\left(\text { Behaviour }_{\mathrm{DC}}, \text { Behaviour }_{\mathrm{GD}}\right)\right. \\ & \left.\times \operatorname{Sim}\left(\text { Component }_{\mathrm{DC}}, \text { Component }_{\mathrm{GD}}\right) \times \operatorname{Sim}\left(\mathrm{AF}_{\mathrm{DC}}, \mathrm{AF}_{\mathrm{GD}}\right)\right\}\end{aligned}$

Where DC represents design conflict, GD represents generalised design case, CF Formatted: Follow-on paragraph style represents changed flow, and AF represents affected flow. Similarity between changed flows $\underline{\text { can be represented as: }}$

$\operatorname{Sim}\left(\mathrm{CF}_{\mathrm{DC}}, \mathrm{CF}_{\mathrm{GD}}\right)=\operatorname{Sim}\left(\right.$ Flow $_{\mathrm{DC}}$, Flow $\left._{\mathrm{GD}}\right) \times \operatorname{Sim}\left(\right.$ Character $_{\mathrm{DC}}$, Character $\left._{\mathrm{GD}}\right)$

$\underline{\text { Similarity between affected flows can be represented as: }}$

$\operatorname{Sim}\left(\mathrm{AF}_{\mathrm{DC}}, \mathrm{AF}_{\mathrm{GD}}\right)=\operatorname{Sim}\left(\right.$ Flow $_{\mathrm{DC}}$, Flow $\left._{\mathrm{GD}}\right) \times \operatorname{Sim}\left(\right.$ Character $_{\mathrm{DC}}$, Character $\left._{\mathrm{GD}}\right)$

By comparing the overall similarities between the formalised deign conflict and the generalised design case, a set of prioritised similarity values are generated: $\left\{\operatorname{Sim}\left(D C, G D_{1}\right), \operatorname{Sim}\left(D C, G D_{2}\right), \ldots, \operatorname{Sim}\left(D C, G D_{n}\right)\right\}$

$\underline{B y}$ exploring and reviewing design cases associated with retrieved generalised design $\underline{\text { cases from higher priority to lower priority, the suitable design cases are chosen as reference }}$ $\underline{\text { solutions for the target design conflict. }}$ 
International Journal of Computer Integrated Manufacturing

\subsection{Results of the industrial example and system implementation}

The example used in previous sections has been processed in this system. Application of the methodology has been partially displayed during the discussion of the methodology. In order to have an overview of the results and the general process in an intuitive way, a tabular form has been used to organise the results (shown in Figure 14).

(Figure 14)

A three-tier web-based pilot system has also been developed to implement the proposed methodology for engineering design change management. The pilot system is partly developed. Integrations with other business systems like PDM, ERP and SCM are going to be done at the next stage of this research. Software systems involved in this prototype include MySQL as an infrastructure of data storage, Tomcat 6.0 as a web server and servlet container, Java enterprise edition (Java EE) as the business implementation architecture, and also Java Server Page (JSP) as a presentation technology. Figure 15 shows an overview interface of design conflict solving of design change analysis. The page shows the final stage of the design conflict solving analysis process, which is trying to get reference solutions from the knowledge repository to help designers work out a viable solution for the current design conflicts.

(Figure 15)

\section{Conclusions and Further Work}

Any design changes either in functional requirement domain or in the physical structure domain will potentially affect operations of other parts. Change propagations and their impacts are difficult to be captured, which makes product design in uncertainty. The authors argue that design change propagation is caused by design conflicts arising from the initial change and 
International Journal of Computer Integrated Manufacturing

changes afterwards. Change propagations are difficult to predict without knowing their preceding change solutions since all following changes are based on the solutions of preceding changes. Knowledge from previous design change cases is an important asset for companies. Many design conflicts arising from change analysis can be tackled by reusing well-formalised and managed knowledge abstracted from previous design cases. In this paper, a methodology for design change management has been proposed to implement these ideas by using modelling method, matrix analytical method and knowledge support. First, the system engineering modelling method captures critical interactions between functions and components. The matrix-based analytical method helps to trace change propagations and identify design conflicts by following mapping relationship between functions and components, and behavioural and spatial connections between components. By using the design conflicts formalisation approach, design conflicts can be formalised based on predefined ontology, Deleted: functional ontology and which makes knowledge reasoning in the knowledge base possible. The framework of the knowledge base is proposed to collect knowledge of design change from previous design cases. With help of the knowledge base and the reasoning method, designers are able to find proper solutions and evaluate their potential impacts. A prototype system has been developed to show that the idea of this paper is technically feasible and can benefit companies with IT technologies.

The emphasis of further work will be put on development of methods for evaluating design change impact in terms of factors of project success. Any changes made in product development need to be evaluated in terms of development time, development risk and development cost. However, in practice, impacts of design changes are normally estimated by experienced engineers or other staff in the company. The results of change impact evaluations 
International Journal of Computer Integrated Manufacturing

could be very inconsistent with estimations from different people who have different experience and different knowledge backgrounds. In the next stage of this research, an approach to integrating with other enterprise systems will be developed. This approach is to acquire knowledge regarding contributions that previous products make to related projects in terms of factors of project success. With help of knowledge acquired, an algorithm will be developed to calculate change impact more accurately.

\section{Acknowledgements}

This project has been supported by the wind turbine design company Vensys Energy AG in Germany and the leading wind turbine manufacturer Goldwind Ltd in China. Some of their engineering designers

provided advice in developing the methodology and the illustrative example.

\section{References}

ALTSHULLER, G. S., 1996. And suddenly the inventor appeared: TRIZ, the theory of inventive problem solving. 2nd ed. Worcester, Mass.: Technical Innovation Center.

ARIYO, O. O., ECKERT, C. M. and CLARKSON, P. J., 2009. Challenges in identifying the knock-on effects of engineering change. International Journal of Design Engineering, 2, 414-431.

BALOGUN, J. and JENKINS, M., 2003. Re-conceiving Change Management:: A Knowledge-based Perspective. European Management Journal, 21(2), 247-257.

CHRISTOPHE, F., BERNARD, A. and COATANÉA, É., 2010. RFBS: A model for knowledge representation of conceptual design. CIRP Annals - Manufacturing Technology, 59(1), 155-158.

CLARKSON, J. and ECKERT, C., 2005. Design process improvement: a review of current practice. London: Springer.

CLARKSON, P. J., SIMONS, C. and ECKERT, C., 2004. Predicting Change Propagation in Complex Design. Journal of Mechanical Design, 126(5), 788-797.

DO, N., CHOI, I. J. and SONG, M., 2008. Propagation of engineering changes to multiple product data views using history of product structure changes. International Journal of Computer Integrated Manufacturing, 21(1), 19 - 32.

ECKERT, C., CLARKSON, P. J. and ZANKER, W., 2004. Change and customisation in complex engineering domains. Research in Engineering Design, 15(1), 1-21.

ECKERT, C. M., KELLER, R., EARL, C. and CLARKSON, P. J., 2006. Supporting change processes in design: Complexity, prediction and reliability. Reliability Engineering \& System Safety, 91(12), 1521-1534.

FEY, V. and RIVIN, E. I., 2005. Innovation on demand: new product development using TRIZ. Cambridge: Cambridge University Press.

HIRTZ, J., STONE, R., MCADAMS, D., SZYKMAN, S. and WOOD, K., 2002. A Functional Basis for Engineering Design: Reconciling and Evolving Previous Efforts. Research in Engineering Design, 13(2), 65-82.

HUANG, G. Q., YEE, W. Y. and MAK, K. L., 2001. Development of a web-based system for engineering change management. Robotics and Computer-Integrated Manufacturing, 17, 255-267.

HUANG, G. Q., YEE, W. Y. and MAK, K. L., 2003. Current practice of engineering change management in Hong Kong manufacturing industries. Journal of Materials Processing Technology, 139(1-3), 481-487.

JARRATT, T. A. W., ECKERT, C. M., WEEKS, R. and CLARKSON, P. J., Environmental legislation as a driver of design. ed. The 14th International Conference on Engineering Design (ICED'03), 19-21 August 2003 Stockholm, Sweden. 
International Journal of Computer Integrated Manufacturing

KEESE, D. A., SEEPERSAD, C. C. and WOOD, K. L., 2009. Product flexibility measurement with enhanced Change Modes and Effects Analysis CMEA. International Journal of Mass Customisation, 3, 115-145.

KELLER, R., ECKERT, C. M. and CLARKSON, P. J., 2009. Using an engineering change methodology to support conceptual design. Journal of Engineering Design, 20(6), 571 - 587.

KOCAR, V. and AKGUNDUZ, A., 2010. ADVICE: A virtual environment for Engineering Change Management. Computers in Industry, 61(1), 15-28.

LEE, H., AHN, H., KIM, J. and PARK, S., 2006. Capturing and reusing knowledge in engineering change management: A case of automobile development. Information Systems Frontiers, 8(5), 375-394.

MCKAY, K., BRAMALl, D., ROGERS, B., CHAPMAN, P., CHEUNG, W. and MAROPOULOS, P., 2003. Design change impact analysis during early design specification. International Journal of Computer Integrated Manufacturing, 16(7), 598 - 604.

OBJECT MANAGEMENT GROUP, 2008. OMG Systems Modeling Language (OMG SysML) VI.1 [online]. Object Management Group. Available from: http://www.omg.org/spec/SysML/1.1/PDF [Accessed 16 May 2009].

OUERTANI, M. Z., 2008. Supporting conflict management in collaborative design: An approach to assess engineering change impacts. Computers in Industry, 59(9), 882-893.

OUERTANI, M. Z. and GZARA, L., 2008. Tracking product specification dependencies in collaborative design for conflict management. Computer-Aided Design, 40(7), 828-837.

PALANI RAJAN, P. K., VAN WIE, M., CAMPBELL, M. I., WOOD, K. L. and OTTO, K. N., 2005. An empirical foundation for product flexibility. Design Studies, 26(4), 405-438.

PIKOSZ, P. and MALMQVIST, J., A comparative study of engineering change management in three Swedish enginnering companies. ed. Design Engineering Technical Conferences and Computers in Engineering Conference, September 13-16 1998 Atlanta, Georgia.

ROUIBAH, K. and CASKEY, K. R., 2003. Change management in concurrent engineering from a parameter perspective. Computers in Industry, 50(1), 15-34.

SHIAU, J.-Y. and WEE, H. M., 2008. A distributed change control workflow for collaborative design network. Computers in Industry, 59(2-3), 119-127.

SUH, N. P., 2001. Axiomatic design: advances and applications. New York: Oxford University Press.

WRIGHT, I. C., 1997. A review of research into engineering change management: implications for product design. Design Studies, 18(1), 33-42. 


\section{Figure list:}

Figure 1 . Design changes between functional and physical domains

Figure 2. Analytical process of design change management

Figure 3 . An inside view of a wind turbine

Figure 4. Functional analysis of cooling system

Figure 5. Analysis of interactions in the cooling system

Figure 6. Composite matrix for change analysis

Figure 7. Process of solving design conflicts

Figure 8 Design conflict occurring

Figure 9. Formalisation of the meta-interactional-model

Figure 10. Ontology development for design change management

Figure 11. Framework of the knowledge system for conflict solving

Figure 12 Reasoning approach to design conflict solving

Figure 13 Comparison of semantic meanings between concepts

Figure 14. Results of the example processed in the knowledge system

Figure 15. Prototype system implementation of CDM 


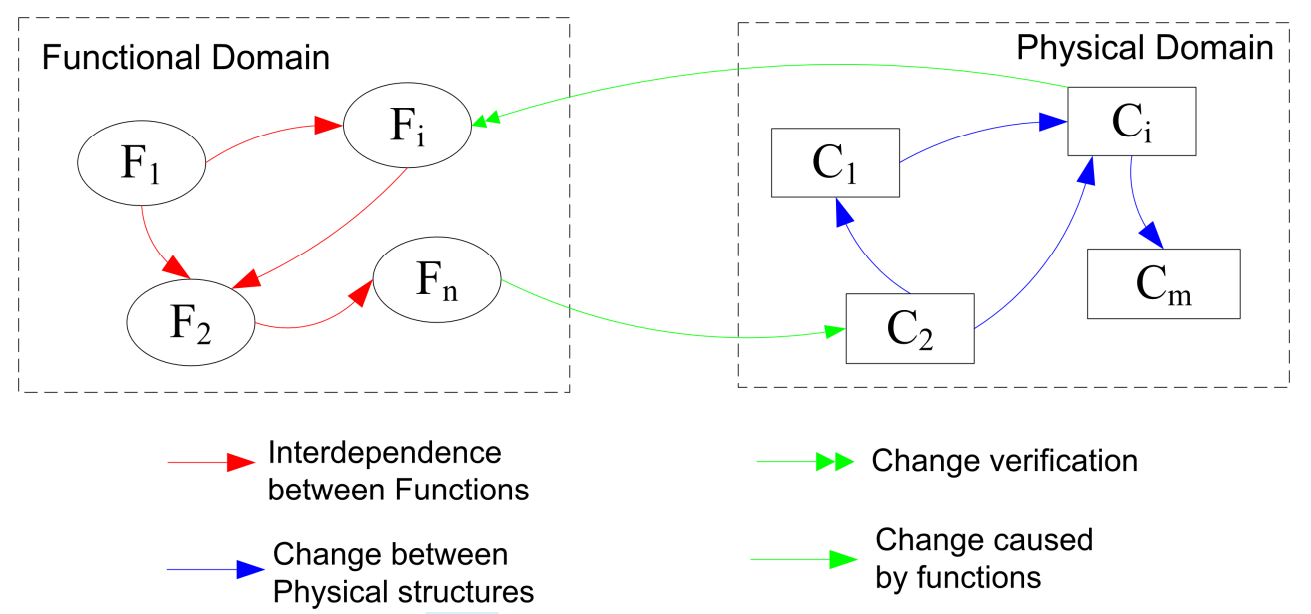

Figure 1. Design changes between functional and physical domains 
Initial change goes to change propagation analysis

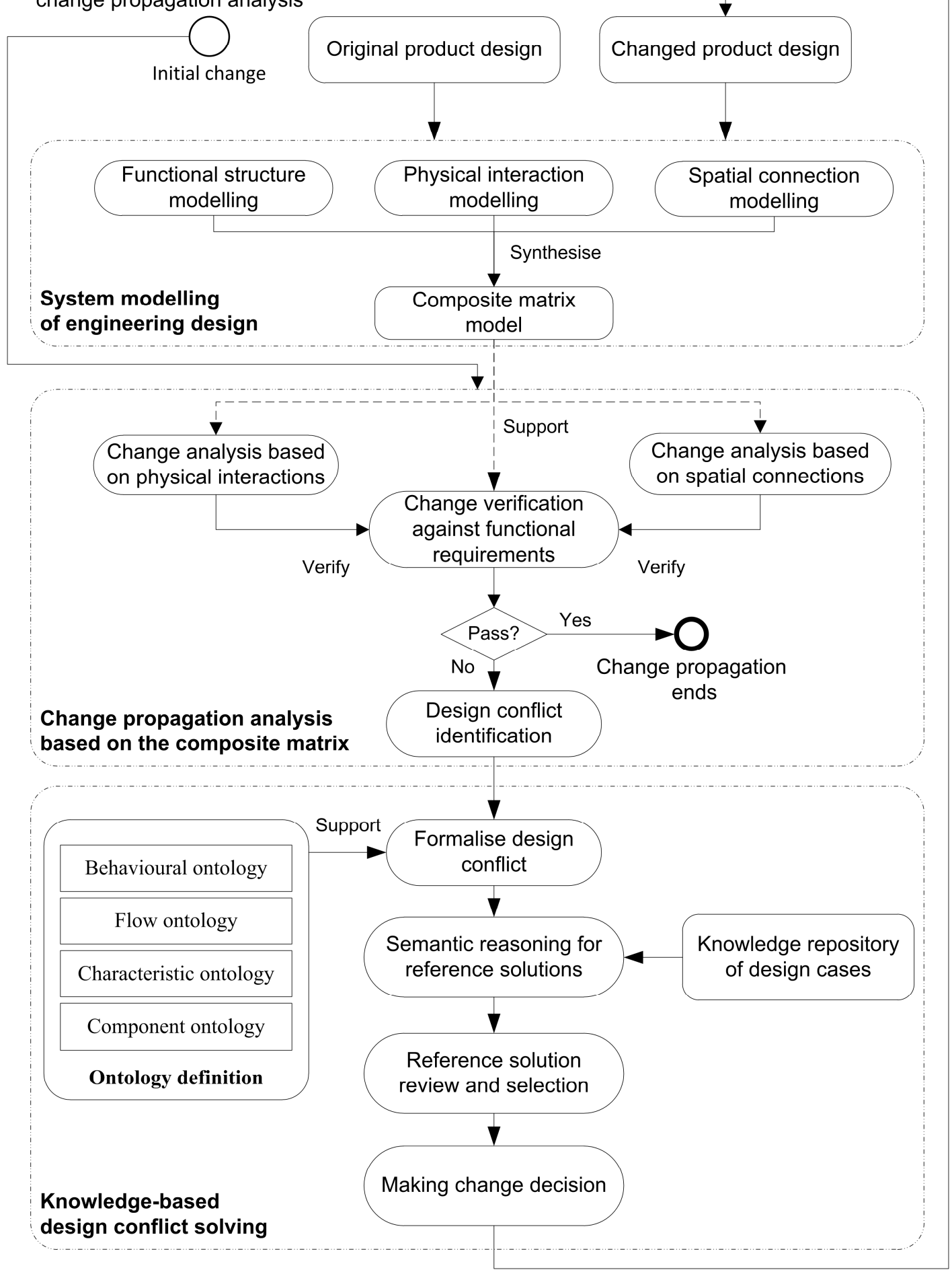

Update design models with the change decision and check further change propagation

Figure 2. Analytical process of design change management 


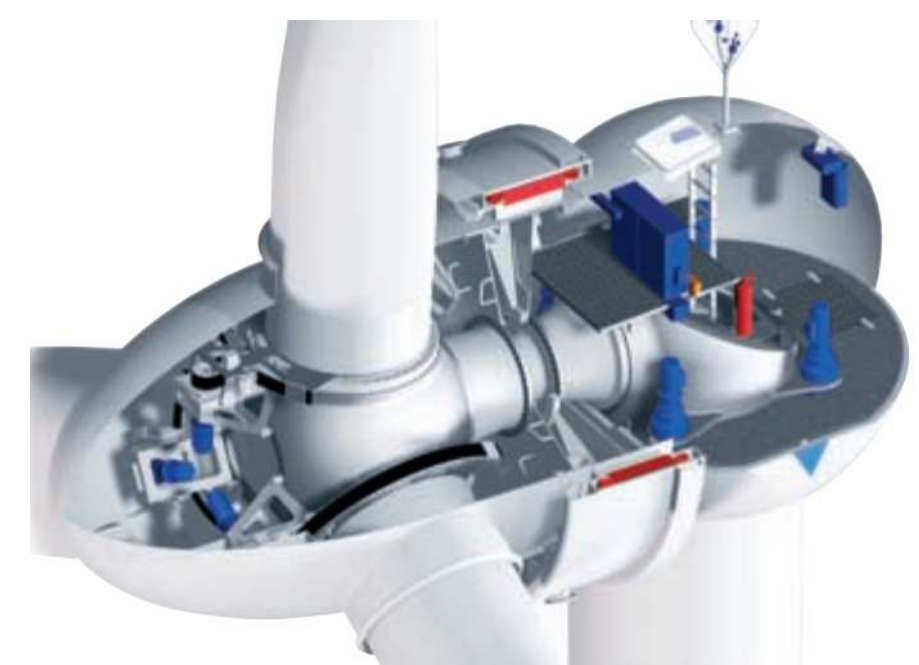

Figure 3. An inside view of a wind turbine

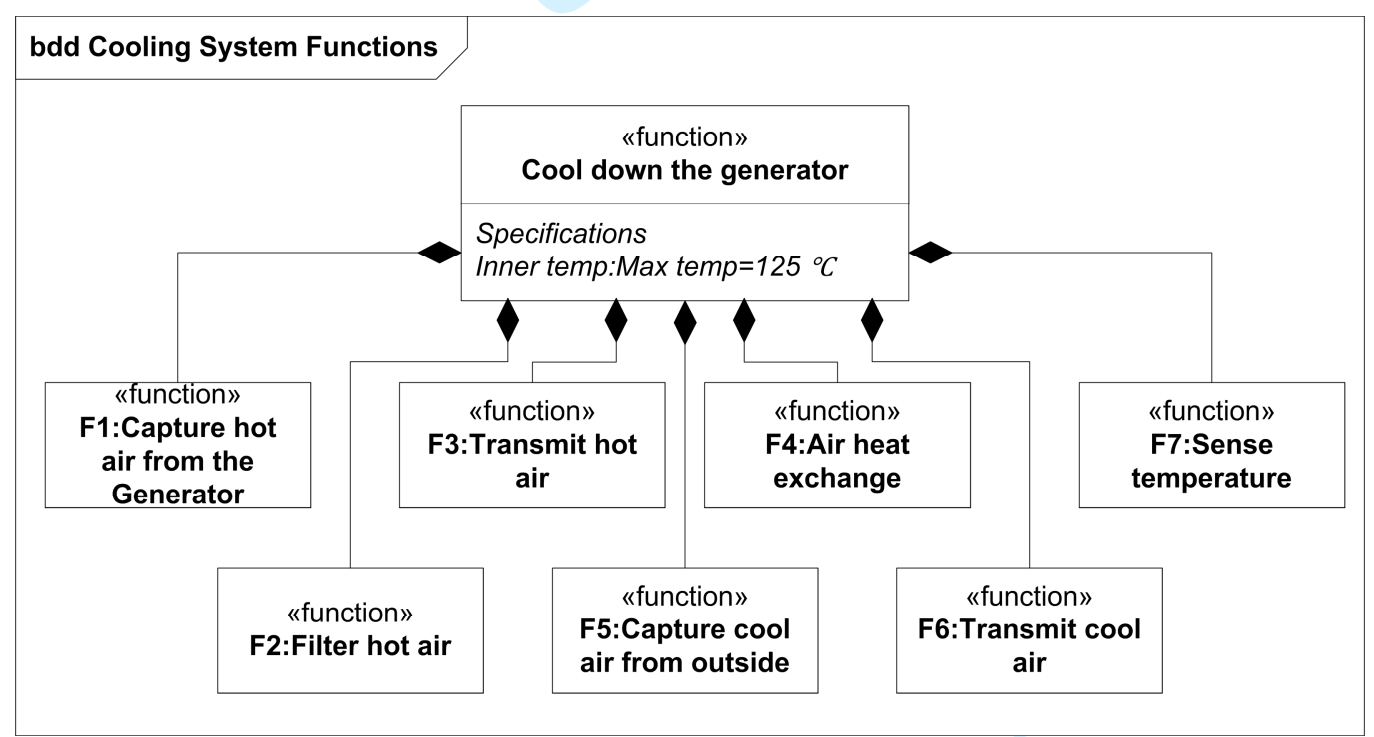

Figure 4. Functional analysis of cooling system 


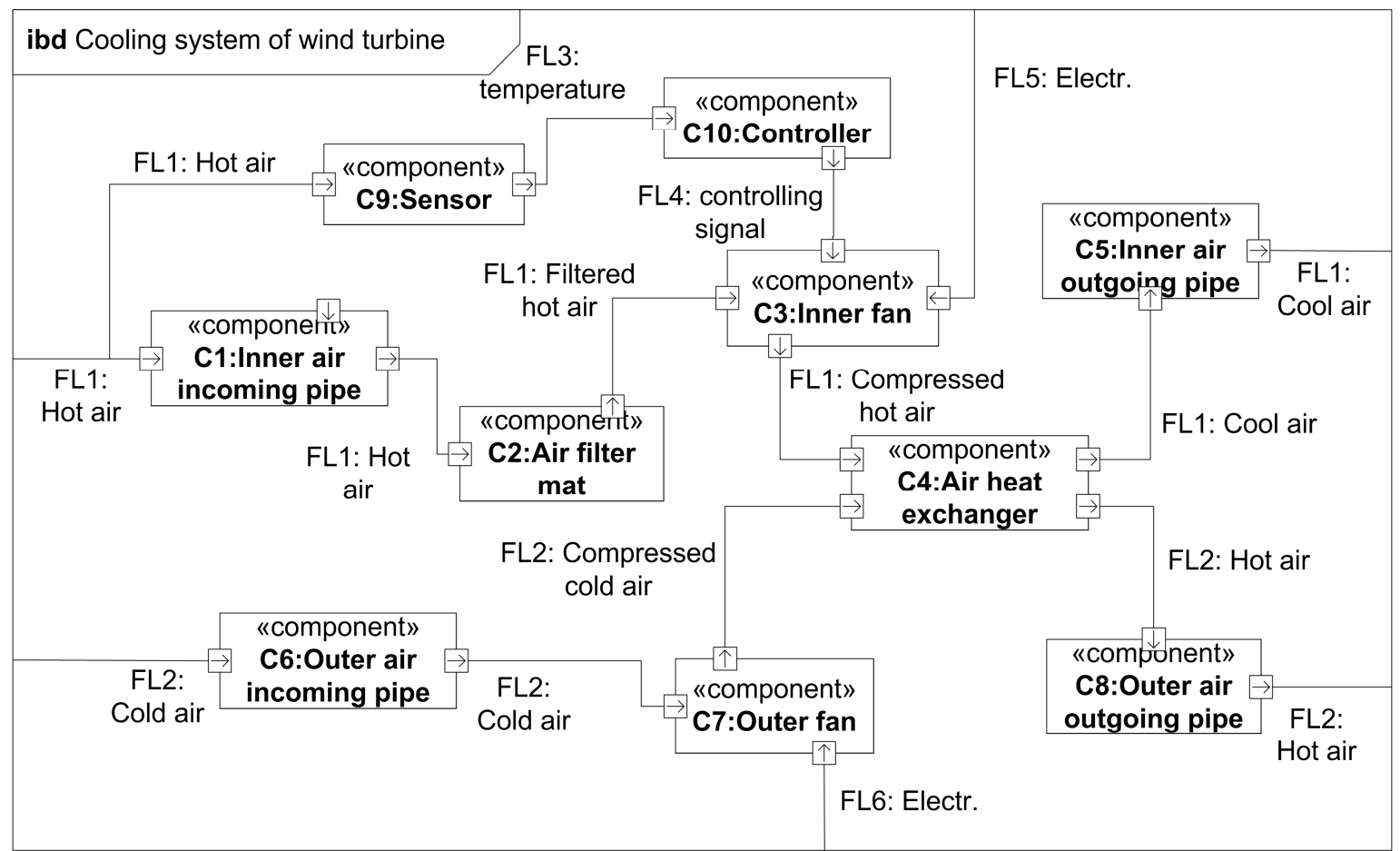

Figure 5. Analysis of interactions in the cooling system

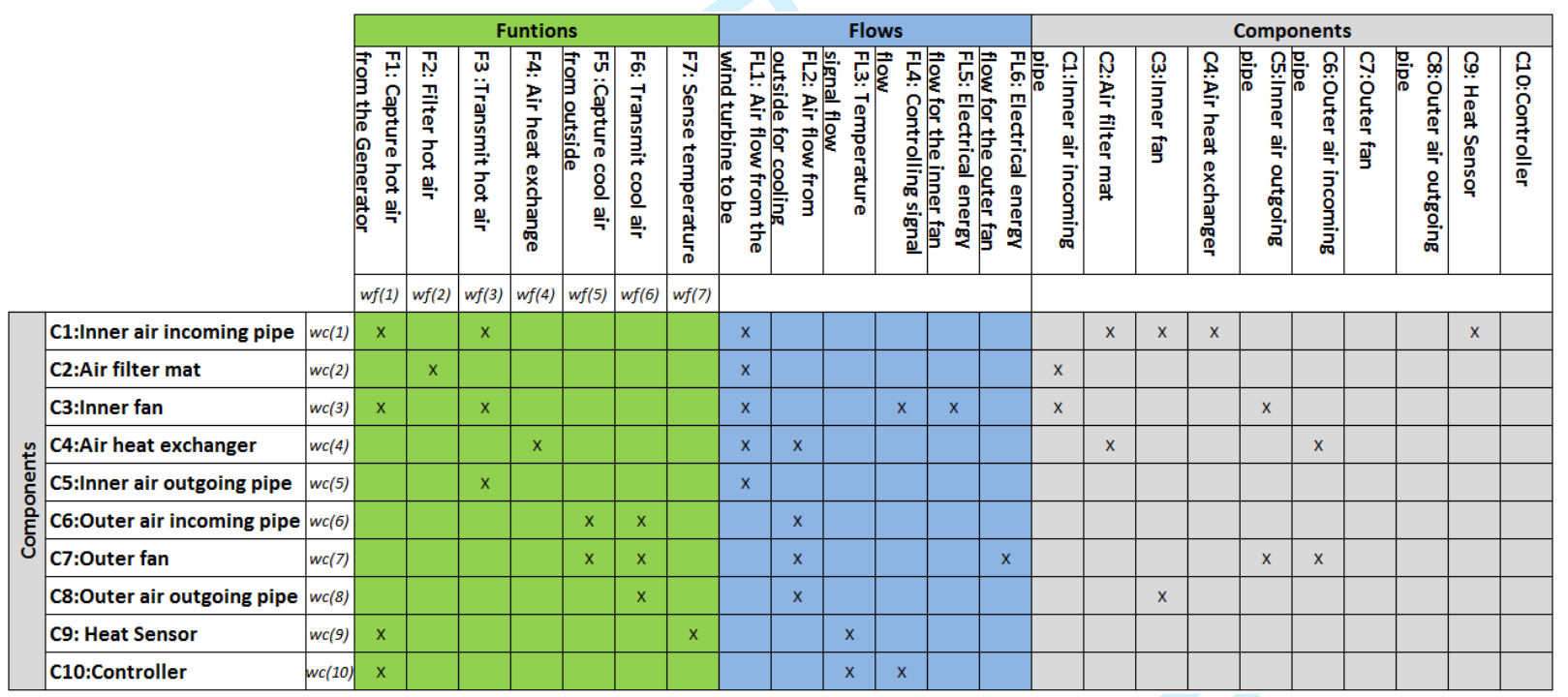

Figure 6. Composite matrix for change analysis 


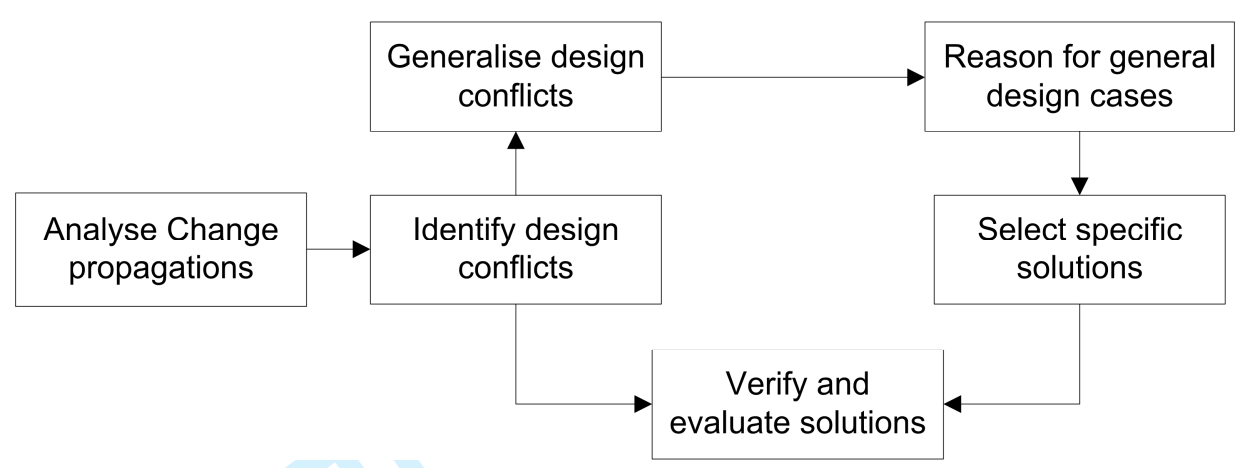

Figure 7. Process of solving design conflicts

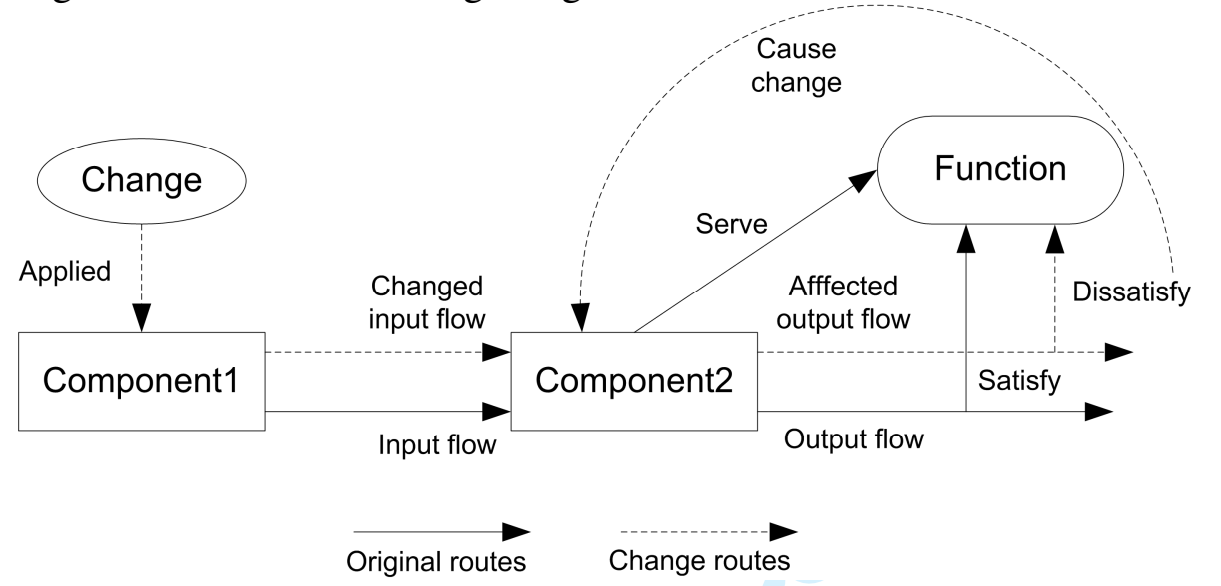

Figure 8 Design conflict occurring

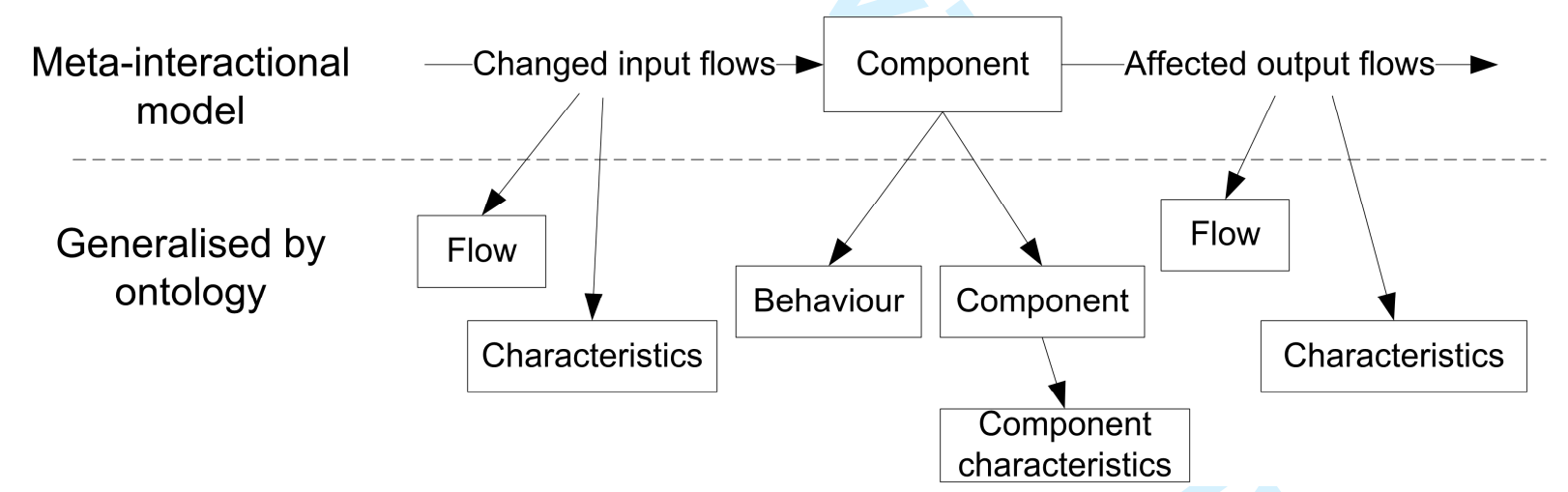

Figure 9. Formalisation of the meta-interaction-model 


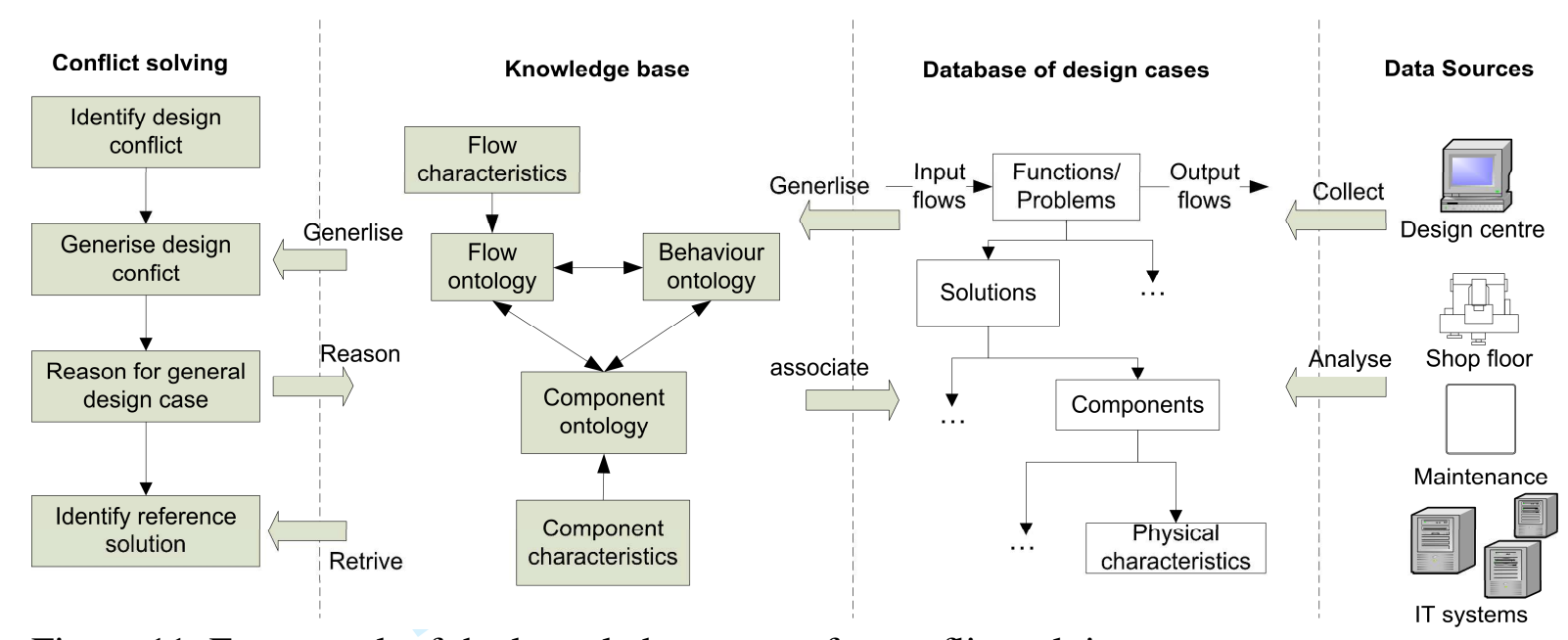

Figure 11. Framework of the knowledge system for conflict solving

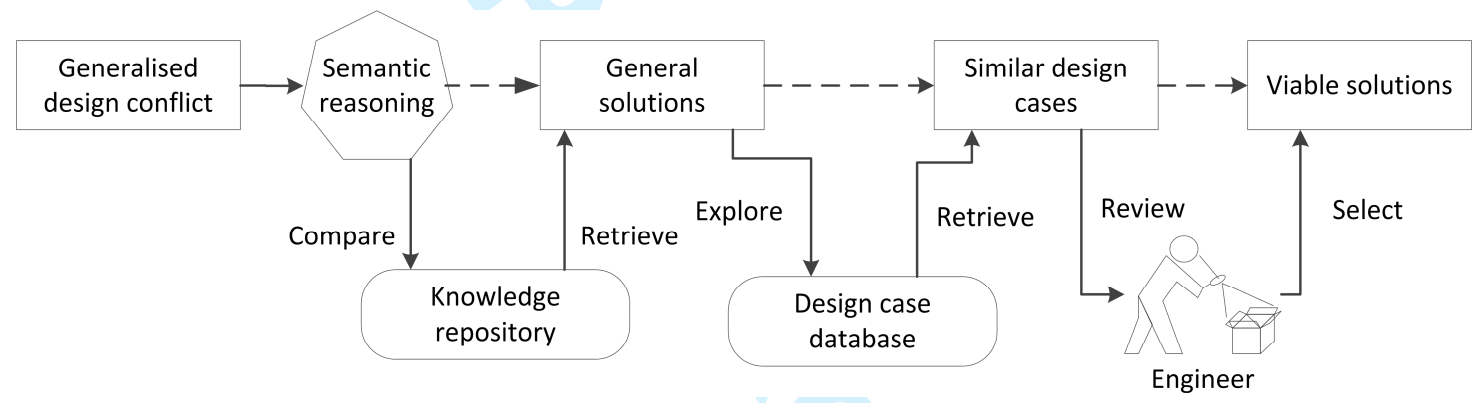

Figure 12 Reasoning approach to design conflict solving

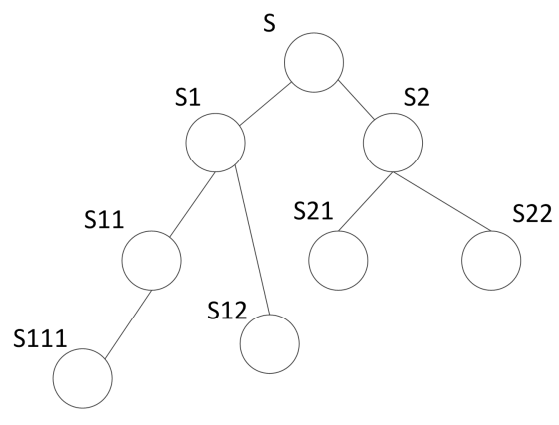

a: Definition of ontology

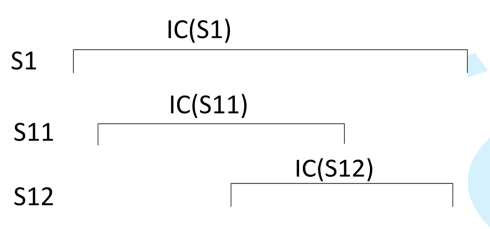

b: Semantic meanings of element S1 and its children

Figure 13 Comparison of semantic meanings between concepts 


\begin{tabular}{|c|c|c|c|c|c|c|c|c|}
\hline \multicolumn{3}{|c|}{ Design conflict description } & \multicolumn{4}{|c|}{ Formalised design conflict } & \multirow{2}{*}{ General solutions } & \multirow{2}{*}{\begin{tabular}{|c|} 
Design cases \\
$\begin{array}{c}\text { Design } \\
\text { documents }\end{array}$ \\
\end{tabular}} \\
\hline Change & Cause & Effect & \multicolumn{2}{|c|}{ Formalisation } & \multicolumn{2}{|c|}{ Generalisation by Ontology } & & \\
\hline \multirow{10}{*}{$\begin{array}{l}\text { Change Air } \\
\text { Filter Mat }\end{array}$} & \multirow{10}{*}{$\begin{array}{l}\text { Lower air } \\
\text { pressure } \\
\text { (FL1) from the } \\
\text { inner air } \\
\text { incoming pipe } \\
\text { (C1) }\end{array}$} & \multirow{10}{*}{$\begin{array}{c}\text { Reduce the } \\
\text { efficiency of } \\
\text { heat } \\
\text { exchanging } \\
\text { (C4) }\end{array}$} & \multirow{2}{*}{$\begin{array}{l}\text { Affected } \\
\text { Function }\end{array}$} & \multirow{2}{*}{$\begin{array}{l}\text { Air heat exchange } \\
\qquad(\mathrm{F} 4)\end{array}$} & Behaviour: & Conduct & \multirow{10}{*}{$\begin{array}{l}\text { 1. Change the } \\
\text { material of the } \\
\text { conduction part; } 2 \text {, } \\
\text { Increase the area of } \\
\text { conduction } \\
\text { interface; } 3 \\
\text { Improve the } \\
\text { structure of air } \\
\text { vessel; } 4 \text {, Increase } \\
\text { the velocity of air } \\
\text { flow }\end{array}$} & \multirow{10}{*}{$\begin{array}{c}\text { 1, Passive } \\
\text { cooling system } \\
\text { of the unclear } \\
\text { reactor (File no } \\
\star \star \star \star) \\
\text { 2, Patent: } \\
\text { DE } \\
\text { 19636591C; } 3, \\
\text { Central air } \\
\text { conditioner } \\
\text { (File no. }{ }^{* \star \star *)} \text { ); }\end{array}$} \\
\hline & & & & & Object: & $\begin{array}{l}\text { Thermal flow, } \\
\text { Gas flow }\end{array}$ & & \\
\hline & & & \multirow{3}{*}{$\begin{array}{l}\text { Changed } \\
\text { input flow }\end{array}$} & \multirow{3}{*}{\begin{tabular}{|c|} 
Air flow from \\
incoming pipe $(F L 1)$ \\
with lowered \\
pressure
\end{tabular}} & Flow: & $\begin{array}{l}\text { Thermal flow, } \\
\text { Gas flow }\end{array}$ & & \\
\hline & & & & & Characteristics & Pressure & & \\
\hline & & & & & Change: & Reduced & & \\
\hline & & & \multirow{3}{*}{$\begin{array}{l}\text { Affected } \\
\text { output flow }\end{array}$} & \multirow{3}{*}{$\begin{array}{c}\begin{array}{c}\text { External hot air from } \\
\text { the exchanger ( } F L 2) \\
\text { with less heat } \\
\text { exchanged }\end{array} \\
\end{array}$} & Flow: & $\begin{array}{c}\text { Thermal flow, } \\
\text { Gas flow }\end{array}$ & & \\
\hline & & & & & Characteristics & Temperature & & \\
\hline & & & & & Change: & Increaced & & \\
\hline & & & \multirow{2}{*}{$\begin{array}{c}\text { Affected } \\
\text { Component }\end{array}$} & \multirow{2}{*}{$\begin{array}{l}\text { Air Heat Exchange } \\
\text { (C4) }\end{array}$} & Component & $\begin{array}{l}\text { Air-Air heat } \\
\text { exchanger }\end{array}$ & & \\
\hline & & & & & Characteristics & $\begin{array}{c}\text { Material, } \\
\text { contact area }\end{array}$ & & \\
\hline
\end{tabular}

Figure 14. Results of the example processed in the knowledge system

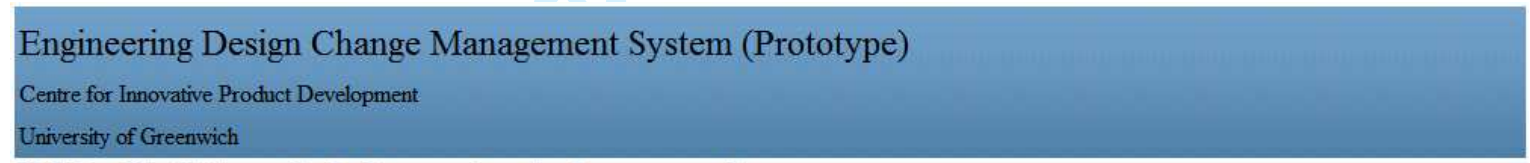

$\underline{\text { EDCM }} \gg$ Wind Turbine $\gg$ Cooling System $\gg$ Improving dust canpture performance

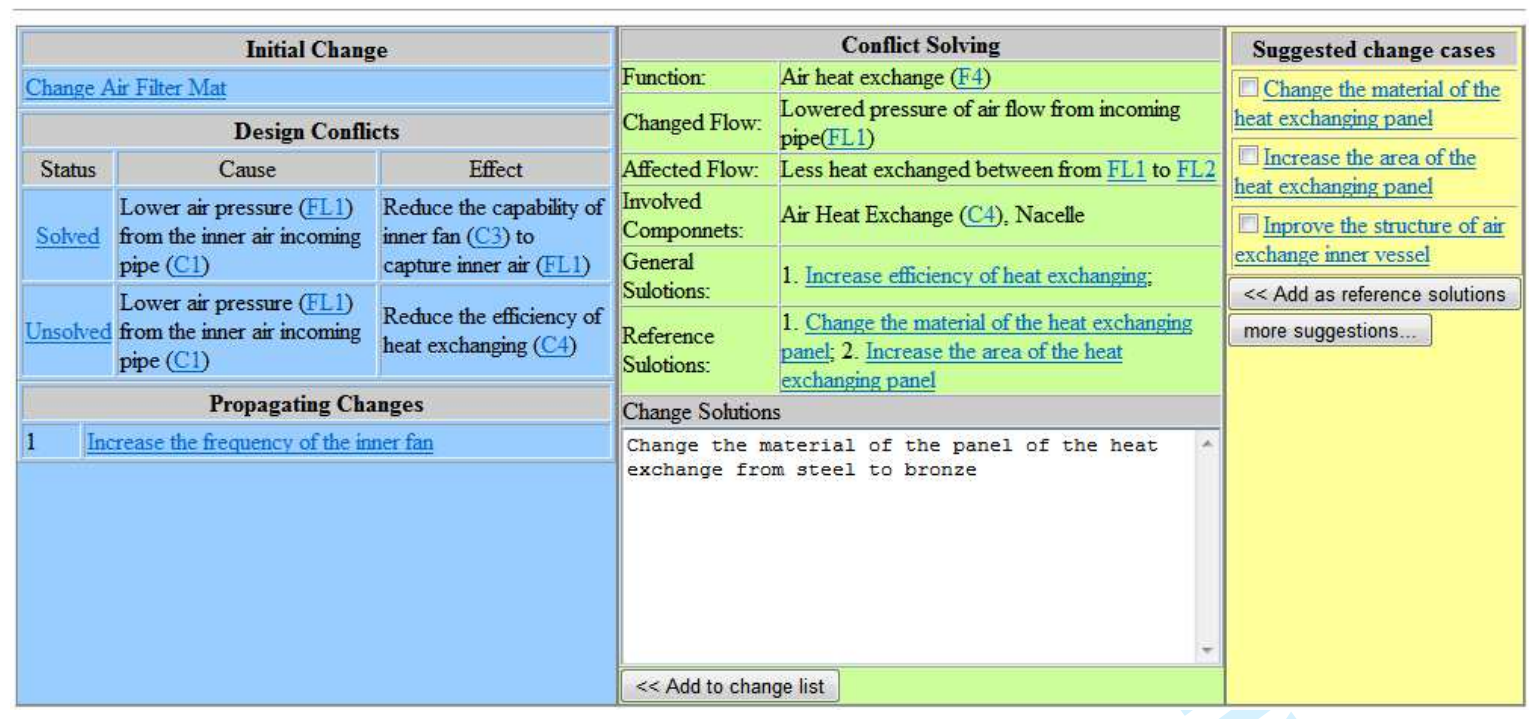

Figure 15. Prototype system implementation of CDM 


\section{Responses to Reviewers' Comments}

\section{Response to the first referee's comments:}

Comments to the Author

This manuscript presents a novel methodology that has been developed to help designers trace, analyse and evaluate engineering changes occurring in the product design phase. However, the major problems about this manuscript are as follows:

1. Both "modelling method" and "matrix based method" have been well developed; it is hard to find innovative points in the proposed methodology.

Response: We do not claim that SysML modelling method is an innovative point in this paper, but it is a necessary tool for clarifying functional requirements and interactional relationship between components.

The composite matrix-based method is new and different from the ways that other researchers proposed, which contains three types of the relationships in one model, which enables to track change propagations dynamically with consideration of three types of relationships together. Therefore it can help identify design conflicts. The composite matrix can repeat as many times as needed to continuously refine the design.

2. The proposed process of design change management (Figure 2) is one of the most important results of this study. It should be better to explain specifically that how to come out the results.

Response: The diagram of design change management has been redrawn and the description of the process has been rewritten in order to be more specific.

3. Why use ontology to proceed the design conflict solving in section 4 ?

Response: Ontology is defined and used to formalise design conflict and problems/functions that previous design cases have resolved/realised. Therefore, a generalised design conflict can be semantically compared with generalised previous solved problems/functions so that reference solution can be found. Development and use of ontology have been presented in section 4.

4. In the manuscript, some paragraphs are too long and should be shortened.

Response: Some parts of the paper have been rewritten or improved to make it more concise.

5. Figures should be simplified to illustrate and support the text.

Response: Some figures have been redrawn and improved 
6. The texts in some figures are too small and not clear.

Response: Some figures have been improved to make them more legible.

\section{Response to the first referee's comments:}

Comments to the Author

Page 5 and page 7: Pikosz 1998 has to be changed to Pikosz and Malquist 1998

Response: Corrected

Page 12: last paragraph before Figure $1:$ How to be sure that finally the solution will be found ? Is there a unique solution to this change propagation process? Please justify and clarify this issue.

Response: This part of the paper is supposed to explain how changes propagate between the functional domain and the physical domain of design, which is one of the findings from analysis of design change management practices. Sorry that the problem was not explicitly given. It has been revised by adding the declaration of the problem from this part of the findings and what this paper is to offer.

The change propagation analytical process is described in section3. A knowledgebased method for solution finding is presented in section 4 with some improvements.

Page 14: Paragraph 3 - section 3.1

When you write "There are three types... and physical structures", Please refer to paper:

F. Christophe, A. Bernard, E. Coatanéa (2010), RFBS: A model for knowledge representation of Conceptual Design, CIRP Annals - Manufacturing Technology, Vol 59/1/2010, pp.155-158 ( doi:10.1016/j.cirp.2010.03.105)

Response: Reference added. Thanks a lot.

In the same section: "By following the mapping... have been determined". This supposes that there is always a solution. Who is going to choose/ to decide/ to validate the changes? A KBE system or a designer? Please comment and justify.

Response: Yes, as an important part of the research, there is a method for finding proper solutions for design conflicts, which is described in section 4 regarding using a 
knowledge-based system to solve design conflicts. The description of section 4 has been enhanced. The expression of this sentence may not be proper. Description of the process has been rewritten and better explained in section 3.1

Page 15 same section: "Futhermore, more spatially... is tolerable." Does this mean that each function corresponds to different performance indicators, with respect to given ranges of possible values (for example, does it has to be between amin and amax)?

Response: At the end of the early product design (conceptual design), functional requirements of the design and their specifications should be clarified. Yes, as you mentioned, the specifications are usually given as ranges of values that the outcomes of the functions will drop in. Any outcomes dropping out of the range means their corresponding functional requirements having not been satisfied and which also means 'intolerable'.

Page 15, same section: "During proposed process...that each change may cause." This is the theory. But how is this done in practice?

Response: This part has been rewritten and better explained how design knowledge is used in design conflict solving. The solution for using knowledge of previous design cases are better explained in section 4 by adding the method of semantic similarity comparison.

Impact evaluation using general knowledge is a part of the further work and will not be discussed in detail in this paper

Page 15: "cooling system needs (be to be suppressed) to be improved"

\section{Response: Corrected}

Page 16: Figure 4: what does "specifications" attribute of "cool down the generator" function represent? Specifications should concern each function. Are all functions independent? Please justify and proof.

Response: The functional specification has been better explained in section 3.3.

Functions are not required to be independent in this proposed methodology. Functional dependency is not concerned in this paper. The change propagation analysis just concerns three types of relationships: mapping relationship between functional requirements and physical components, interactional relationships between components and spatial relationships between components. 
Page 17: Figure 5 shows the interaction... functional requirements." This is true but what is proposed in your method to face and solve/ help solving this problem? Please justify and clarify this point.

Response: The proposed composite matrix is used to help solve this problem. Please refer to section 3.4

Page 18: "A marked cell... in the row." This means that there is a kinematic assembly liaison between these two components? Please clarify.

Response: Yes, the spatial relationships represented by marked cells include static and kinematic physical connections based on assembly relationships but excludes any flow-based interaction. A bit more explanation has been added in Section 3.3 paragraph 3.

Page 18: "In this case, .......holding capacity $750 \mathrm{~g} / \mathrm{m} 2$. ." In this case, the change of the characteristics of the component is enough (a filter with different characteristics is adopted) but sometimes, for example, because of improvements of resistance and mechanical characteristics, one component has to be transformed in several ones. How this aspect is managed? Please clarify and justify.

Response: Method of change propagation analysis can accommodate multiple component changes. When change decision has been made, designers need to restructure those three models and the composite model as well. If the change decision involves changes to multiple components, those components will be modelled in those re-structured models. Any propagated changed caused by them will be further analysed. The process is described in section 3.1, where the diagram has been redrawn and the description of the process has been rewritten.

Page 21:

"a knowledge based (instead of base)"

Response: Corrected

"then, the generalized the (to be deleted) problem"

Response: Corrected

"similar cases": what does it mean? How the similarity analysis is proceeded?

Response: The idea of similarity analysis has been added in section 4.3

"Figure 8 shows... a design conflict." It seems that there is no "conflict" within Figure 8. Please clarify. 
Response: Figure 8 has been improved. It's not accurate to name the model as a design conflict. It's actually a meta -model of interactional behaviour which would potentially cause design conflict if the affected output flow causes related functions cannot be realised correctly. The description has been improved.

\section{Page 22:}

"The flow ontology... The Characterics ontology..." In Figure 9, there is no flow ontology, no characteristics ontology. Please clarify and put it coherent.

Response: The flow ontology and behaviour ontology have been added. They were previously combined together in the first part of the diagram. The characteristics ontology and its relation to the flow ontology has been displayed in the same figure.

"The behaviour ontology (please clarify) defines the ("the" has to be deleted) how the flow.."

\section{Response: Corrected}

“... and the component ontology...". What does it mean? Is this a catalog of standard components? Please justify.

Response: The component ontology defined a collection of components that are used in the company. It's not supposed to be an industrial standard. It's a part of the company's knowledge base that defines components used in their business and is categorised.

"The functional ontology includes three types of ontology, namely the behaviour ontology and the flow ontology.". If I count well, only two types of ontology, not three. Please clarify and justify.

Response: Sorry, a typo. Corrected.

“... to develop proposed... change management." What does it mean in practice? Please clarify.

Response: Improper expression. It's changed.

Page 24:

Figure 12 shows... design conflicts." This means that the system proposes some alternative solutions, then the designer chooses one of them. But what about the 
propagation of this choice and the obtention of the new "coherent" system with the new characteristics? Please clarify and justify.

Response: When reference solutions have been retrieved and selected, designers need to work out a proper solution based on the reference solutions. Then the designers need to go back with the improved design and re-structure the models. They will do the change propagation analysis again and make sure there is no significant impact on other functions. The process of design change analysis has been improved in Figure 2, which better explains the approach.

"is caused by design (instead of deing)"

\section{Response: Corrected}

Concerning the reference list: please decide either this is necessary to develop all the "et al." list of authors or not. But please, put it coherent in the list and in the text.

Response: Improved

Page 40, Figure 11: please change "volecity" to "velocity" in the second column from the right.

\section{Response: Corrected}

\section{Editor Comments}

1. Please revise your paper and respond to the referees comments in a separate doc file and submit this with the revised manuscript.

2. Please have your paper proof read by a native English Speaker or a person more familiar with the English language.

3. Please update your references to IJCIM format as they should be alphabetical not numbered. Use the authors names in the text ie (Newman, 2007) Also please check the journal website

http://www.informaworld.com/smpp/title content=t713804665 db=all

4. Please check for IJCIM appropriate references as well. You currently have only a few references from IJCIM or none.

http://www.informaworld.com/smpp/title $\sim$ content=t713804665 db=all

5. Please resubmit your paper in 3 (THREE) .doc word files formatted in SINGLE Column representing the paper Text, Figures and Tables. 